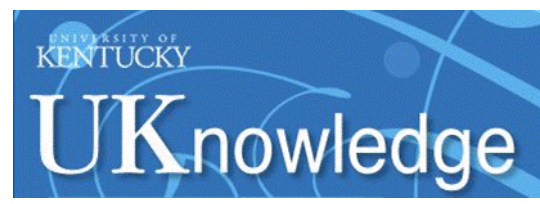

University of Kentucky

UKnowledge

8-1-2005

\title{
A Brief History and Current Status of a Dental Therapy Initiative in the United States
}

David A. Nash

University of Kentucky, danash@uky.edu

Ron J. Nagel

US Public Health Service

Follow this and additional works at: https://uknowledge.uky.edu/ohs_facpub

Part of the Dentistry Commons

Right click to open a feedback form in a new tab to let us know how this document benefits you.

\section{Repository Citation}

Nash, David A. and Nagel, Ron J., "A Brief History and Current Status of a Dental Therapy Initiative in the United States" (2005). Oral Health Science Faculty Publications. 13.

https://uknowledge.uky.edu/ohs_facpub/13

This Letter to the Editor is brought to you for free and open access by the Oral Health Science at UKnowledge. It has been accepted for inclusion in Oral Health Science Faculty Publications by an authorized administrator of UKnowledge. For more information, please contact UKnowledge@lsv.uky.edu. 


\title{
A Brief History and Current Status of a Dental Therapy Initiative in the United States
}

\author{
Notes/Citation Information \\ Published in the Journal of Dental Education, v. 69, no. 8, p. 857-859. \\ (C) 2005 American Dental Education Association \\ Reprinted by permission of Journal of Dental Education, Volume 69, 8 (August 2005). Copyright 2005 by \\ the American Dental Education Association. http://www.jdentaled.org
}


Reprinted by permission of Journal of Dental Education, Volume 69, 8 (August 2005). Copyright 2005 by the American Dental Education Association. http://www.jdentaled.org 


\section{A Brief History and Current Status of a Dental Therapy Initiative in the United States}

Dear Dr. Alvares:

As per your invitation, we are providing a brief review of the history of the current attempt to add a dental therapist to the dental team in the United States, as well as report on the status of the effort.

In November 2000, Oral Health America sponsored a conference in Boca Raton, Florida, on the surgeon general's report, Oral Health in America. At that meeting Dr. David Nash invited Dr. Dominick DePaola, president of The Forsyth Institute, and Dr. Wendy Mouradian, professor of pediatrics and pediatric dentistry at the University of Washington, to discuss the potential that introducing a New Zealandstyle "school dental nurse/therapist" could have on addressing oral health disparities among America's children. As a result of that discussion, a larger meeting of interested parties was held in February 2001 at The Forsyth Institute in Boston. The intention of the Forsyth meeting was to consider how such a new member of the dental team could function in the delivery system and to seek funding for a training program and experimental initiative. A result of the Boston meeting was the decision to focus on working with American Indians/Alaska Natives, as this population experiences an inordinate disparity in oral health. Additionally, the Tribes are sovereign, so the ability to develop and deploy "pediatric oral health therapists" could be facilitated in such an environment.

Concurrent with these discussions, the Alaska Native Tribal Health Consortium (ANTHC) was beginning the development of dental health aides, under the provisions of the Congressionally authorized Alaska Community Health Aide Program (CHAP). Initially, the program called for development of a primary dental health aide (PDHA) and an expanded function dental health aide (EFDHA). The PDHA would function primarily as a community dental educator but also provide preventive services under the general supervision of a dentist. The EFDHA would work under the direct supervision of a dentist and serve as an expanded function dental assistant. A contract to provide training for these two levels of dental health aide was awarded to the University of Kentucky in 2002. The first series of training programs for the PDHA and EFDHA will be completed in September 2005.

Ron Nagel was responsible for working with the Alaska Native Tribal Health Consortium (ANTHC) to develop the dental health aide program. He was also involved in the conversations emanating from the Forsyth meeting. Consequently, a third level of dental health aide was conceptualized, a dental health aide therapist (DHAT), that is, a pediatric oral health therapist. Discussions proceeded within the ANTHC regarding the training of DHATs and sources of funding for such. The School of Dentistry at the University of Otago in New Zealand agreed to accept six Alaska Native students per year into their dental therapy training program. Funding to support training and travel was obtained from the Rasmuson Foundation. In February 2003, six Alaska Native students traveled to New Zealand to participate in a two academic year curriculum to be trained as dental therapists. In May of that year, Nash arrived at the University of Otago for a previously arranged sabbatical to study the work of the school dental nurse/ dental therapist in New Zealand and its potential applicability to the disparities problem in the United States. Six additional students from Alaska were sent to study in New Zealand in February 2004, and six more in February 2005. Four of the initial six students completed the program in December 2004 and are currently serving brief preceptorships in preparation for practicing dental therapy in remote Alaskan Tribal villages. The therapists will provide primary oral health care for children under the general supervision of a dentist. The other two initial enrollees are in the process of completing training requirements.

The American Dental Association learned of the Alaska students studying dental therapy in New Zealand and the intention for them to return to Tribal programs to practice. At its October 2003 Annual Session, the American Dental Association (ADA) 
House of Delegates passed a resolution calling for a task force to "explore options for delivering high quality oral health care to Alaska Natives." The Alaska Native Oral Health Access Task Force submitted its report to the ADA Board of Trustees in August 2004. Based on the task force's recommendations, the Board advanced to the House of Delegates, at the ADA's October 2004 Annual Session, a resolution with fourteen elements to address access to oral health care for Alaska Natives, with two dealing specifically with the advanced level dental health aide therapist: 1) "the ADA work with the ADS [Alaska Dental Society] and tribal leaders to seek federal funding with the goal of placing a dental health aide (i.e., a Dental Health Aide I or II) trained to provide oral health education, preventive services, and palliative services (except irreversible procedures such as tooth extractions, cavity and stainless steel crown preparations, and pulpotomies) in every Alaska Native village that requests an aide" (emphasis added); and 2) "The ADA is opposed to non-dentists making diagnoses or performing irreversible procedures." The resolution passed the House of Delegates overwhelmingly on a voice vote.

Subsequently (in November/December 2004), the ADA attempted to amend the Indian Health Care Improvement Act, which was in the process of being reauthorized by the Congress in the closing days of the 108th Congress. This act authorizes development and operation of the Community Health Aide Program, which includes dental health aides. House Bill HR 2440 was amended at legislation mark-up to read "ensure that no dental health aide is certified under the program to perform treatment of dental caries, pulpotomies, or extractions of teeth." However, the ADA's amendment was not successful because reauthorization of the Indian Health Care Improvement Act was not accomplished by the $108^{\text {th }}$ Congress. Reauthorizing legislation will have to be reintroduced in the current $109^{\text {th }}$ Congress.

The ADA has constituted a Task Force on Workforce Models. At its April 2005 meeting, several individuals/organizations were asked to testify regarding perspectives on the dental workforce of the future. Nash was asked to testify on the concept of adding a pediatric oral health therapist to the dental workforce. The task force is to present its report and recommendations to the ADA House of Delegates in October 2005.

The ADA also retained four consultants who were paid to independently examine the access prob- lem of Native Americans in Alaska. These consultants were Dr. Howard Bailit and Dr. Tryfon Beazoglou of the University of Connecticut, Dr. Amid Ismail of the University of Michigan, and Dr. Thomas Kovaleski, Dental Director of the South Central Foundation in Alaska, one of the twelve Tribal associations. They submitted a report to the ADA, dated April 2005, entitled "Integrated Dental Health Program for Alaska Native Populations." Among their recommendations was that the dental therapists' model be replaced with a lesser-trained individual, a community oral health provider (COHP). These individuals would have organizational and management duties in the proposed integrated system and would also have clinical responsibilities including atraumatic restorative treatment (ART), treatment of mild periodontal disease by prophylaxis and scaling, and management of acute pain and infection under the direction of dentists. Unlike dental therapists, they would not be able to provide definitive therapy such as permanent restorations, pulpal therapy, or simple extractions. At the time of submission of this letter to the editor, this proposal had been advanced to the ANTHC leadership and discussed by the dental directors of the ANTHC, but had not been formally responded to by the chief executive officer of the ANTHC.

The Alaska State Board of Dentistry, at the instigation of the Alaska Dental Society, has challenged the legality of dental therapists practicing in the Tribal health care system. Its challenge is currently under review by the state's attorney general. Again, no response from the attorney general had been issued at the time of this letter.

It should be noted that the ADA Task Force that visited Alaska in April 2004 indicated to the Tribal leadership that the ADA would develop a volunteer program in which dentists from other states would voluntarily spend time in Tribal villages caring for Native Alaskans without access to care. The program, named "Operation Backlog," was prominently publicized by the ADA; however, no provisions have as yet been made by the ADA for dealing with the logistics associated with temporary licensure and deployment of volunteer dentists. Thus, over one year later, no volunteers have been sent to Alaska under the ADA program.

At the most recent ADA Board of Trustees meeting, June 12-14, 2005, the Board unanimously passed a resolution supporting the idea of litigation, should it become necessary, against dental therapists 
practicing in the Tribal health care system in Alaska. The Board also authorized "an advertising campaign up to a $\$ 150,000$ level to educate Alaskan natives and others about the risks of allowing non-dentists to perform irreversible procedures."

Two articles describing the concept of a pediatric oral health therapist, as well as the significant history of attempts to implement a school dental nurse/therapist model in the United States, have been published by Nash: "Developing a Pediatric Oral Health Therapist to Help Address Oral Health Disparities Among Children," J Dent Educ 2004;68:820, and "Developing and Deploying a New Member of the Dental Team: A Pediatric Oral Health Therapist," J Pub Health Dent 2005;65:48-55. A third article by Nash and Nagel ("Confronting Oral Health Disparities Among American Indian/Alaska Native Children: The Pediatric Oral Health Therapist") will appear in the August 2005 issue of the American Journal of Public Health.

—David A. Nash, D.M.D., M.S., Ed.D.

William R. Willard Professor of Dental Education

Professor of Pediatric Dentistry

College of Dentistry

University of Kentucky

Lexington, KY 40536

859-323-2026 phone; 859-323-4685 fax danash@email.uky.edu

—Ron J. Nagel, D.D.S., M.P.H.

U.S. Public Health Service Indian Health Service

Alaska Native Tribal Health Consortium 4201 Tudor Centre Drive, Suite 120

Anchorage, AK 99508 